Volume 9, No.5, September - October 2020

International Journal of Advanced Trends in Computer Science and Engineering

Available Online at http://www.warse.org/IJATCSE/static/pdf/file/ijatcse199952020.pdf

https://doi.org/10.30534/ijatcse/2020/199952020

\title{
Enhancing Routing for Wireless Ad-Hoc Networks to Improve Quality of Service in Mobile Learning
}

\author{
Itzamá López-Yáñez ${ }^{1}$, Oscar Camacho-Nieto ${ }^{1}$, Antonio Alarcón-Paredes ${ }^{2}$ \\ Centro de Innovación y Desarrollo Tecnológico en Cómputo, Instituto Politécnico Nacional, Mexico, \\ ilopezy@ipn.mx,ocnieto8@gmail.com \\ ${ }^{2}$ Universidad Autónoma de Guerrero, Mexico, aalarcon@uagro.mx
}

\begin{abstract}
The quality of mobile learning relies strongly on two relevant factors: quality of content and pedagogical techniques on one hand; and quality of the service related to connectivity and performance of the computing and communications platform on the other hand. The latter aspect, network performance, is in turn dependent on the quality of frame routing in wireless ad hoc networks, since this performance will affect both network link quality and battery life. An existing approach to this routing intends to maximize battery life, and among its exponents is a scheme which determines a route by computing first a minimum spanning tree between the source and destination nodes. The proposal presented in this paper finds this final route in one step, by means of a simple algorithm which uses binary decision diagrams to compute the minimum spanning tree for the sought-after route.
\end{abstract}

Key words :mobile learning, quality of service, wireless ad hoc networks, enhancing routing.

\section{INTRODUCTION}

The beginnings of the third millennium have been highlighted by the extraordinary changes brought to society in general and individuals in particular, by the accelerated progress of technology. Computers have especially undergone a tremendous evolution, going from huge, expensive, power-hungry, heavy, and cumbersome contraptions with tiny memory and computing capacity, to become these small and convenient devices with astounding computing capacities and until recently unthinkable amounts of storage capacity. The new digital computers are powerful devices able to process and move the user information in a friendly manner, with impressive applications supported by the advances in communications technologies. The former leads to an increasingly rich and broad spectrum of options, uses, and applications that frequently boggle the minds of members from previous generations. In this sense, education is undoubtedly immersed as well in this tsunami of changes, so much that such emerging concepts as mobile learning is al-ready a reality.

The role of quality of service in mobile learning is quite transcendental. This depends, in part, on one relevant factor: the quality of content and the pedagogical techniques underpinning such content [1].New mobile learning technologies have shifted the priorities towards what learner needs. If these challenges are properly tackled, educational contents and pedagogical techniques are bound to improve. Quite rightly, in [2] it is remarked that, as mobile communication technologies progress, the challenges faced by educators consist on testing new pedagogical models and instruments in order to guarantee the quality of contents and educative processes.

Beside the quality of content and pedagogical techniques, there is another relevant factor for the quality of service in mobile learning, which consists on the quality of service related to connectivity and performance of the computing and communications platform and collaborative learning [3,4].

This second relevant factor - quality of service related to connectivity and performance of the computing and communications platform - is in turn strongly dependent on the quality of frame routing in wireless ad hoc networks. This dependency is due to the manner in which frame routing performance will affect both network link quality and battery life, which are critical in mobile learning [5]. In a broader sense, it is important for students to have an appropriate infrastructure which fulfils certain minimal requirements, in order to obtain good results in mobile learning. Such requirements include: mobile devices with sufficient memory; an appropriate display with respect to the available content; and of course communications functionalities; optionally, intelligent mobile devices are desirable, where available.

Routing and connectivity are important issues in ad-hoc networks [6,7]. The reduction of the transmission power in the physical layer of the OSI communications model increases the traffic carrying capacity of the network[8]. In order to solve this kind of problems in wireless ad hoc networks, the authors of [9] show that each node should be connected to $\log (\mathrm{n}) \mathrm{NN}$ in order to guarantee connectivity. 
The current solutionsto maximize battery life tend to converge to a minimum spanning tree in an iterative procedure [10]. The proposal made in the current paper builds this final route in one step, by using a simple algorithm which uses binary decision diagrams to compute the minimum spanning tree for a given source to destination route.

The rest of this paper is organized as follows: section 2 is dedicated to explaining the relationship between mobile learning and wireless ad hoc networks. The third section describes the use of minimum spanning trees to improve routing in multi-hop networks, while the operation of spanning trees using binary decision diagrams is discussed in section 4. The proposal of this paper is then presented in section 5 , leaving conclusions for section 6 , and finally the references are included.

\section{MOBILE LEARNING IN WIRELESS AD HOC NETWORKS}

The raw concept of Mobile Learning has to do with the use of mobile technology in educational environments [11]. Through the use of mobile devices interconnected in wireless ad hoc networks, mobile learning enables teacher and students to create virtual worlds [12].

We have witnessed the recent accelerated development of mobile devices, wireless communication and network technologies, which we can see today as a part of campus environment for teachers and students [3]. Naturally, mobile learning is done on mobile devices interconnected through wireless ad hoc networks[13].

Several educative projects where mobile devices interconnected in wireless ad hoc networks are described in [13], which allow educators to freely experiment with mobile learning. Finally, there is a business training program offered in Singapore, which is called eBusiness on the Move.

Such successful projects offer a stimulus for researchers to look for more and better technological solutions to improve mobile learning environments [14]. The concept of Ambient Networking integrates ideas from all across communications, with a set of control functionalities (mainly) at the network level at its core. Such functions may well be implemented atop present and future connectivity technologies, so long as they expose certain information and capabilities. By employing these control functions as an umbrella over other network level technologies, convergence and migration of existing and new technologies are facilitated.

In every mobile learning environment, the quality of service related to connectivity and performance of the computing and communications platform is a critical issue. This is because mobile learning generates a strong demand of computational resources, as well as communications facilities, in order to offer adequate conditions for all processes of mobile learning to occur uninterrupted, which in turn facilitates a successful mobile learning [15].

However, wireless ad hoc networks present new challenges, since continuous end-to-end connectivity cannot be maintained under these conditions, information content needs to be differentiated and offered different services $[16,17]$.

\section{ROUTING IN WIRELESS AD HOC NETWORKS}

According to [18], mobile ad hoc networks (MANETS) are characterized by multiple entities. Wireless ad hoc means devices of MANETS are typically hand-held devices with lower power capacities [19].The authors of [20] propose that ad-hoc networks enable any kind of infrastructure.

On the other hand, [21] discusses the problem of service placement. In order to facilitate communication within the network, and guarantee service placement among other things, the main objective is to determine correct routes, enabling timely communication among them, and doing the latter in an efficient manner: path construction should consume as little overhead and bandwidth as possible.

On describing communication protocols, [22] states that routing in wireless ad hoc networks is of particular interest. In [23], a taxonomy of routing protocols for MANETS is included in that paper, which contains five categories.

1. Source-initiated (reactive or on-demand). One of themost widely referred routing algorithms is Dynamic SourceRouting (DSR).

2. Table-driven (proactive). An instance of this kind of routing protocol is Destination-Sequenced Distance-Vector (DSDV) which is based on the Bellman-Ford routing algorithm.

3. Hybrid combine the power of on-demand and table-driven routing protocols; a well-known example is Zone Routing Protocol (ZRP).

$\begin{aligned} & \text { 4. Location-aware (geographical). } \\ & \text { Location-Aided Routing (LAR). }\end{aligned}$
For example, the

5. Multipath: create multiple routes from source to destination. The Split Multipath Routing (SMR) protocol is an example.

Exploring the first category of the previous taxonomy, [24] analyzes two on-demand routing protocols: AODV and DSR. Indeed, their simulation results show significant increases in packet delivery ratio and decreases in packet latency.

Independently from the taxonomical level to which it belongs, a MANET routing protocol faces a critical issue, which in turn is immersed in the sustainable debate: energy costs control. Thus, the goal is to achieve a more efficient power management. In this regard, [25] reviews energy efficient algorithms and protocols joint with power control to improve energy efficiency. 
Several alternatives for efficient routing protocols in MANETS have been devised [18], yet dynamic power control is a viable one, particularly when comparing against traditional routing protocols regarding power efficiency, as [10] correctly point. The existing schemes maximizes battery life through a minimum spanning tree, which is defined in [26-28].The authors of [29] and [30] created a dynamic power controlled routing scheme by using a minimum spanning tree.

Following this idea, [31] have been using MST for routing and energy reduction. It is important to note the efforts that researchers have made, worldwide, in applications of computational intelligence in various areas of human activity [32-78]. And the application of different models and computational intelligence algorithms in this type of MANETS-related tasks should be emphasized [87-89].

A notable case is that of [90], because "simulation results show that our proposed algorithm is very well for big area".

\section{SPANNING TREES AND BINARY DECISION DIAGRAMS}

This section describes one of the central topics for the development of the current paper proposal. First, Binary Decision Diagrams (BDDs) are presented, in order to later establish their relationship with MST, given that the proposal made in the current paper builds this final route in one step, by using a simple algorithm which uses BDDs to compute the MST for a given source to destination route.

According to [91] Binary Decision Diagrams are very useful to represent Boolean functions, which allows to perform certain tasks related to circuit design and verification applications. Bryant is recognized as the creator of this branch of science and technology [92]. Currently a large number of international research teams are working on projects related to the subject.. In Figure 1 an example of ROBDD for a certain boolean function is shown.

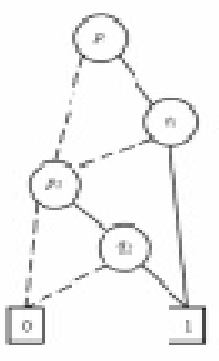

(1)

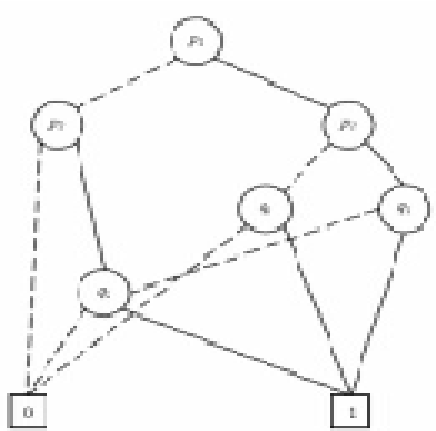

(b)
Figure 1. BDDs for boolean function [(p1)AND(q1)]OR[(p2ANDq2)]: (a) with ordering $p 1<q 1<p 2<q 2$, and (b) with ordering $p 1<p 2<q 1<q 2 ; \operatorname{low}(v)$ children are represented with dotted lines, while high(v) children are represented with solid lines
After BDDs were stirred, ideas soon appeared in the specialized literature, where the possibility of representing MSTs through representations using and BDDs was expressed. In this context, Sangireddy and Somani ventured into the use of BDDs in reconfigurable hardware [93], especially in the design of specialized lookup schemes. The advancement in speed was brutal: the authors got results of throughput of up to 229.3 millions of lookup results per second on dedicated hardware.

\section{ENHANCING MANET ROUTING WITH MSTS AND BDDS}

As was explained previously, one important alternative to improve the quality of service in mobile learning is to enhance the underlying networking technology; if this is done in a more energy-efficient manner, even better. Now, taking advantage of the use of mobile devices inherent to mobile learning, we can assume that connectivity will be realized by means of MANETs in many cases; thus, improving network operation and energy consumption in such a setting would be congruent with the goal mentioned above.

In particular, the use of MSTs and BDDs has been previously explored in order to use dynamic power control in wireless ad hoc networks routing. The proposal of this paper is to take one very successful application of MSTs to MANET routing [30], and modify it by calculating the MST using the algorithm introduced in [94].

An illustration of the proposed method operation is presented in Fig. 2, Fig. 3, and Fig. 4. Our proposal offers the advantage of computing the MST for that route with low complexity - which is $\mathrm{O}(\log 3|\mathrm{~V}|$ where $\mathrm{V}$ is the set of nodes — thanks to the algorithm in [94].

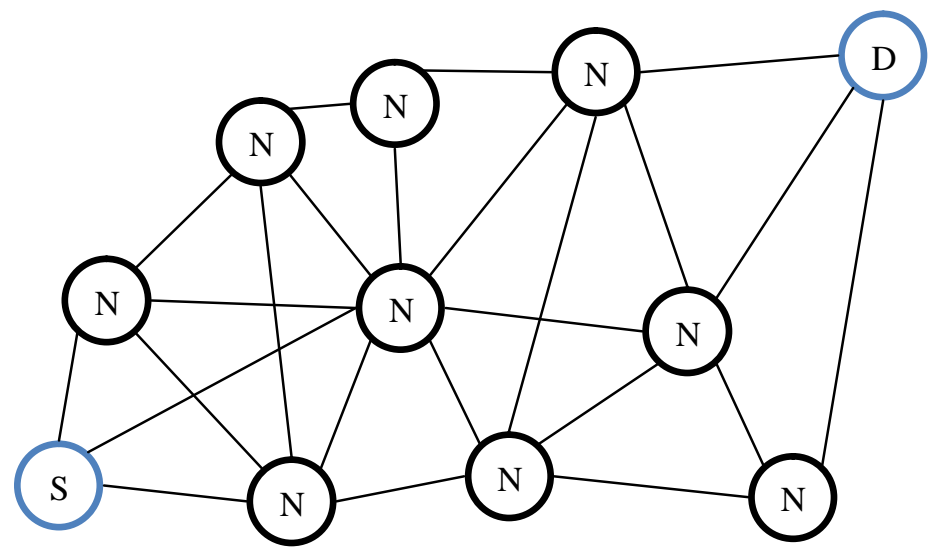

Figure 2. Step 1: initial setting for the proposed method, with nodes $\mathrm{S}$ and $\mathrm{D}$ indicated

The worst-case scenario is that the final route is already one iteration away from the initial state, and that the corresponding power savings are meagre. In this situation, the improvement in battery life may be evened out by the 
increased computational strain incurred, thus implying a low cost and low risk situation.

However, according to [29] and [30] power savings of up to $60 \%$ may be achieved by using variable-range power control, although this is originally done in several iterations. By building a MST representing the network topology (using information which has already been gathered), the final route is determined in one step, reaching the target power savings in one iteration. Since the algorithm followed has low complexity, it is to be expected that the power consumption incurred will be relatively small, both due to the computing power needed and to the time employed.

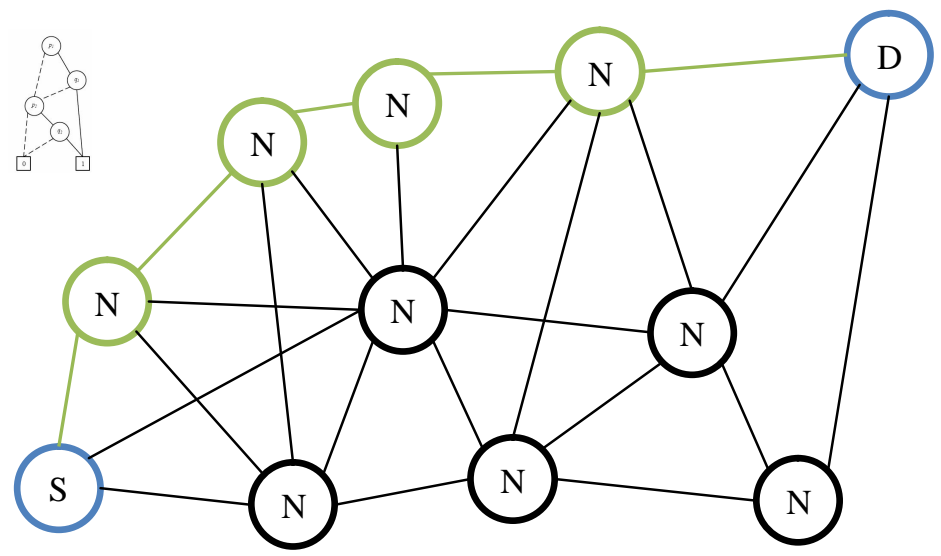

Figure 3. Steps 2 and3: topology represented on a BDD, and MST from S to D built from the BDD; the nodes and links present in the MST are indicated in green

Thus, greater power savings are to be expected. The natural implication of these lesser power consumption is a longer battery life, which is a major concern for mobile devices. With such increased uninterrupted operation time, a more flexible experience is offered to the student, thus enabling a richer, more satisfying, and better learning process. This latter goal is, of course, the final objective of mobile learning.

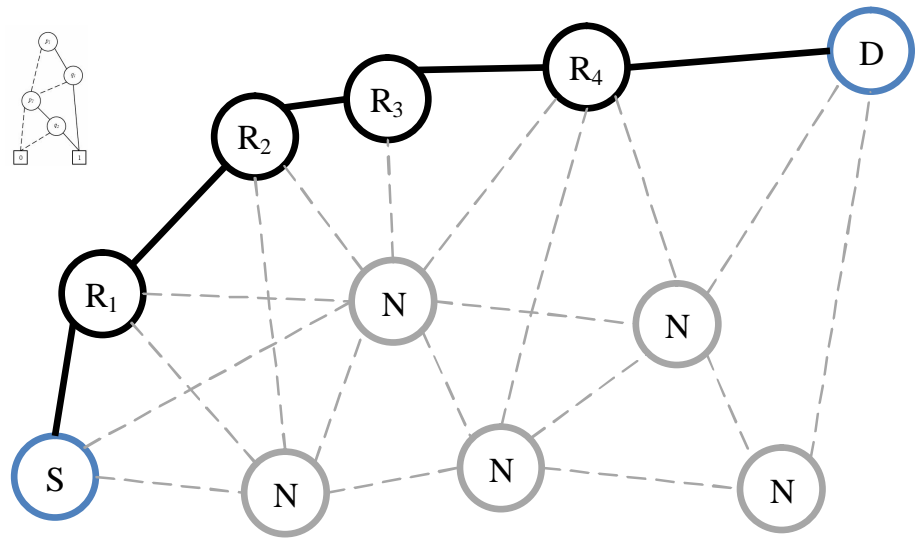

Figure 4. Step 4: all nodes in the MST are made redirectors for the route from $\mathrm{S}$ to $\mathrm{D}$

\section{CONCLUSION}

Among the different alternatives to improve the quality of service of mobile learning, a viable path is that of ensuring a better quality of service at the communications and computing infrastructure. In this sense, and taking into consideration that thanks to its mobility component, mobile learning will most likely be realized on mobile devices, one particular area of interest to reach the aforementioned goal is to enhance the operation of wireless ad hoc networks. More specifically, in this paper a proposal regarding MANETs routing protocols has been presented. The objective in this proposal is to develop a more efficient method of path building for routing in variable power transmission, both in the sense of lower power consumption, little computing processing, and extended battery life.

By computing the final route in only one step instead of several, greater power savings (of up to 60\%) are achieved in less time, which impacts positively on the battery life of the mobile device. This longer operational period for the mobile device implies in turn a better learning experience for the student involved in mobile learning, in diverse and varied topics of science and engineering [95-99].

\section{ACKNOWLEDGEMENT}

The authors want to thank the InstitutoPolitécnico Nacional, Mexico (SecretaríaAcadémica, EST, CIDETEC, COFAA), the CONACYT and SNI for their support in the development of this work.

\section{REFERENCES}

1. H. Crompton, H. and J. Traxler. Learning with mobile devices, in Advanced Methodologies and Technologies in Modern Education Delivery, IGI Global, pp. 793-808, 2019.

2. R. Sepúlveda-Lima, C. Yáñez-Márquez, I. López-Yáñez, and O. Camacho-Nieto. A Novel Solution to the Secure Exchange of Environmental Engineering Education Data,International Journal of Engineering Education, Vol. 28, pp. 1380-1387, 2012.

3. M. D. Lytras, H. Mathkour, H. I. Abdalla, C. Yáñez-Márquez, and P. O. De Pablos. The Social Media in Academia and EducationResearch R-evolutions and a Paradox: Advanced Next Generation Social Learning Innovation, J. UCS, vol. 20, pp. 1987-1994, 2014.

4. M. M. De Luis, A. J. Argüelles Cruz, A. V. Uriarte Arcia, and C. Yáñez-Márquez. Green information technology influence on car owners' behavior: Considerations for their operative support in collaborative eLearning and social networks, Computers in Human Behavior, Vol. 51, pp. 792-802, 2015. 
5. C. H. Leung, and Y. Y. Chan. Mobile Learning: A New Paradigm in Electronic Learning, in Proceedings of ICALT'03, IEEE Computer Society, pp. 76-80., 2003.

6. I. López-Yáñez, O. Camacho-Nieto, C. Yáñez-Márquez, and A. V. Uriarte-Arcia. Fast route convergence in dynamic power controlled routing for wireless ad-hoc networks,IEEE Latin America Transactions, Vol. 11, pp. 607-608, 2013.

7. P. Gupta, and P. Kumar. Critical Power for Asymptotic Connectivity, in Proceedings of 37th IEEE Conference on Decision and Control, pp. 1106-1110,1998.

8. P. Gupta, and P. Kumar. The Capacity of Wireless Networks, IEEE Transaction on Information Theory, IT-46, pp. 388-404, 2000.

9. F. Xue, and P. Kumar. The number of neighbors needed for connectivity of wireless networks, Wireless Networks, Vol. 10, pp. 169-181, 2004.

10. S. K. Sarkar, T. G. Basavaraju, and C. Puttamadappa. Ad hoc mobile wireless networks: Principles, Protocols, and Applications, Taylor \& Francis Group, Boca Raton., 2008.

11. M. Aldape-Pérez, C. Yáñez-Márquez, O. Camacho-Nieto, and A. J. Argüelles-Cruz. A New Tool for Engineering Education: Hepatitis Diagnosis using Associative Memories,International Journal of Engineering Education, Vol. 28, pp. 1399-1405, 2012.

12. J. Traxler. Defining, Discussing and Evaluating Mobile Learning, International Review on Research in Open and Distance Learning (IRRODL), Vol. 8, 2007, pp. 1-12., 2007.

13. C. Houser, P. Thornton, and D. Kluge. Mobile Learning: Cell Phones and PDAs for Education, in Proceedings of ICCE'02, IEEE Computer Society, pp. 1149-1150, 2002.

14. N. Niebert, A. Schieder, J. Zander, and R. Hancock. Ambient Networks: Co-operative Mobile Networking for the Wireless World, John Wiley \& Sons, Ltd., Chichester, England., 2007.

15. K. Mouri, H. Ogata, N. Uosaki, and E. Lkhagvasuren. Context-aware and Per-sonalization Method based on Ubiquitous Learning Analytics, Journal of Universal Computer Science, Vol. 22, pp. 1380-1397, 2016.

16. D. N. Kanellopoulos. Recent Progress on QoS Scheduling for Mobile Ad Hoc Networks, Journal of Organizational and End User Computing (JOEUC), Vol. 31, pp. 37-66, 2019.

17. Y. Villuendas-Rey, C. Yáñez-Márquez, and J. L. Velázquez-Rodríguez. Generic extended multigranular sets for mixed and incomplete information systems,Soft Computing, Vol 24, pp. 6119-6137, 2020.

18. K. P. Kumar, and B. P. Babu. A Simple and Cost-Effective Anomaly Detection Paradigm on the
Basis of Computational Intelligence for Mobile Ad-Hoc Networks from a Security Viewpoint. In Computer Science On-line Conference (pp. 78-86). Springer, Cham., 2019.

19. S. Ajmal, A. Rasheed, A. Qayyum, A. Hasan. Classification of VANET MAC, Routing and Approaches A Detailed Survey, Journal of Universal Computer Science, Vol. 20, pp. 462-487, 2014.

20. E. M. Royer, and C. K. Toh. A Review of Current Routing Protocols for Ad Hoc Mobile Wireless Networks, IEEE Personal Communications, Vol. 6, pp. 46-55, 1999.

21. G. Wittenburg, and J. Schiller. Service Placement in Ad Hoc Networks, Springer, London, 2012.

22. H. König. Protocol Engineering, Springer-Verlag, Berlin Heidelberg, 2012.

23. A. Boukerche, M. Z. Ahmad, D. Turgut, and B. Turgut. A Taxonomy of Routing Protocols for Mobile Ad Hoc Networks, in A. Boukerche, (ed.), Algorithms and protocols for wireless, mobile ad hoc networks, John Wiley \& Sons Inc., Hoboken, New Jersey, pp. 129-163, 2009.

24. L. Qin, and T. Kunz. On-demand Routing in MANETs: The Impact of a Realistic Physical Layer Model Hypermedia Systems in the Future, in Proceedings of ADHOC-NOW 2003, pp. 37-48J.

25. J. Zhu, B. Bensaou, and F. Naït-Abdesselam. Power Control Protocols for Wireless Ad Hoc Networks, in A. Boukerche, (ed.), Algorithms and protocols for wireless, mobile ad hoc networks, John Wiley \& Sons, Inc., Hoboken, New Jersey, pp. 315-352, 2009.

26. A. Frieze. On the value of a random minimum spanning tree problem, Discrete Applied Mathematics, Vol. 10, pp. 47-56, 1985.

27. J. Steele. Growth Rates of Euclidean Minimal Spanning Trees with Power Weighted Edges Coverage, The Annals of Probability, Vol. 16, pp. 1767-1787, 1988.

28. F. Avram, and D. Bertsimas. The Minimum Spanning Tree Constant in Geometrical Probability and Under the Independent Model: A Unified Approach, The Annals of Applied Probability, Vol. 2, pp. 113-130, 1992.

29. J. Gomez, and A. Campbell. Using Variable-Range Transmission Power Control in Wireless Ad Hoc Networks, IEEE Transactions on Mobile Computing, Vol. 46, pp. 87-99, 2007..

30. J. Gomez, and A. Campbell. PARO: Supporting Dynamic Power Controlled Routing in Wireless Ad Hoc Networks, Wireless Networks, Vol. 9, pp. 443-460, 2003.

31. L. Liu, X. Li, J. Jin, Z. Huang, M. Liu, and M. Palaniswami. Graph-Based Routing, Broadcasting and Organizing Algorithms for Ad-Hoc Networks, in K. Stefan, (ed.), Wireless Ad Hoc Networks, InTech, Croatia, pp. 55-73, 2012. 
32. S. Cerón-Figueroa, C. López-Martín, and C. Yáñez-Márquez. Stochastic gradient boosting for predicting the maintenance effort of software-intensive systems,IET Software, Vol. 14, pp. 82-87, 2020.

33. A. V. Uriarte-Arcia, I. López-Yáñez, and C. Yáñez-Márquez. One-hot vector hybrid associative classifier for medical data classification, PloS one, Vol. 9, e95715, 2014.

34. A. García-Floriano, A. Ferreira-Santiago, O. Camacho-Nieto, and C. Yáñez-Márquez. A machine learning approach to medical image classification: Detecting age-related macular degeneration in fundus images, Computers \& Electrical Engineering, Vol. 75, pp. 218-229, 2019.

35. M. E. Acevedo, C. Yáñez-Márquez, and M. A. Acevedo. Associative models for storing and retrieving concept lattices,Mathematical Problems in Engineering, Vol. 2010, 356029, pp. 1-27, 2010.

36. J. E. Luján-García, C. Yáñez-Márquez, Y. Villuendas-Rey, and O. Camacho-Nieto. A Transfer Learning Method for Pneumonia Classification and Visualization. Applied Sciences, Vo. 10, no. 8, 2908, 2020.

37. M. E. Acevedo-Mosqueda, C. Yáñez-Márquez, and I. López-Yáñez. Alpha-Beta bidirectional associative memories: theory and applications, Neural Processing Letters, vol. 26, pp. 1-40, 2007.

38. I. Salgado-Ramos. C. Yáñez-Márquez, O. Camacho-Nieto, and I. Chairez-Oria. Adaptive control of discrete-time nonlinear systems by recurrent neural networks in quasi-sliding mode like regime,International Journal of Adaptive Control and Signal Processing, Vol. 31, pp. 83-96, 2017.

39. S. Dong, Q. Fang, B. J. Falaye, G. H. Sun, C. Yáñez-Márquez, and S. H. Dong. Exact solutions to solitonic profile mass Schrödinger problem with a modified Pöschl-Teller potential,Modern Physics Letters A, Vol. 31, 1650017, 2016.

40. E. Guzmán, O. Pogrebnyak, C. Yañez, and L. P. S. Fernandez. Morphological transform for image compression, EURASIP Journal on advances in signal processing, vol. 2008, p. 426580, 2008.

41. A. V. Uriarte-Arcia, I. López-Yáñez, C. Yáñez-Márquez, J. Gama, and O. Camacho-Nieto. Data stream classification based on the gamma classifier,Mathematical Problems in Engineering, Vol. 2015, Article 939175, pp. 1-17, 2015.

42. G. H. Sun, C. Y. Chen, H. Taud, C. Yáñez-Márquez, and S. H. Dong. Exact solutions of the 1D Schrödinger equation with the Mathieu potential. Physics Letters A, 126480, 2020.

43. R. L. Ulloa-Cazarez, C. López-Martín, A. Abran, and C. Yáñez-Márquez. Prediction of online students performance by means of genetic
programming,Applied Artificial Intelligence, Vol. 32, pp. 858-881, 2018.

44. J. C. Ramirez Velez, C. Yáñez-Márquez, and J. P. Córdova Barbosa. Using machine learning algorithms to measure stellar magnetic fields,Astronomy \& Astrophysics, Vol. 619, A22, pp. 1-13, 2018.

45. A. García-Floriano, C. Yáñez-Márquez, and O. Camacho-Nieto. Detection of Age-Related Macular Degeneration in Fundus Images by an Associative Classifier,IEEE Latin America Transactions, Vol. 16, pp. 933-939, 2018.

46. R. C. López, G. H. Sun, O. Camacho-Nieto, C. Yáñez-Márquez, C., and S. H. Dong. Analytical traveling-wave solutions to a generalized Gross-Pitaevskii equation with some new time and space varying nonlinearity coefficients and external fields,Physics Letters A, Vol. 381, pp. 2978-2985, 2017.

47. A. Ferreira-Santiago, C. López-Martín, and C. Yáñez-Márquez. Metaheuristic optimization of multivariate adaptive regression splines for predicting the schedule of software projects, Neural Computing \& Applications, Vol. 27, pp. 2229-2240, 2016.

48. I. Salgado, I. Chairez, O. Camacho, and C. Yañez. Super-twisting sliding mode differentiation for improving PD controllers performance of second order systems, ISA transactions, vol. 53, pp. 1096-1106, 2014.

49. Y. Villuendas, C. Yanez, and C. Rey. Attributes and cases selection for social data classification,IEEE Latin America Transactions, Vol. 13, pp. 3370-3381, 2015.

50. A. Ramirez, I. Lopez, Y. Villuendas, and C. Yanez. Evolutive improvement of parameters in an associative classifier,IEEE Latin America Transactions, Vol. 13, pp. 1550-1555, 2015.

51. I. López-Yáñez, A. J. Argüelles-Cruz, O. Camacho-Nieto, and C. Yáñez-Márquez. Pollutants time-series prediction using the Gamma classifier, International Journal of Computational Intelligence Systems, vol. 4, pp. 680-711, 2011.

52. J. L. Velázquez-Rodríguez, Y. Villuendas-Rey, O. Camacho-Nieto, and C. Yáñez-Márquez. A Novel and Simple Mathematical Transform Improves the Perfomance of Lernmatrix in Pattern Classification,Mathematics, Vol. 8, 732, pp. 1-46, 2020.

53. Y. Villuendas-Rey, C. F. Rey-Benguría, O. Camacho-Nieto, and C. Yáñez-Márquez. Prediction of High Capabilities in the Development of Kindergarten Children,Applied Sciences, Vol. 10, 2710, pp. 1-29, 2020.

54. I. López-Yáñez, L. Sheremetov, and C. Yáñez-Márquez. A novel associative model for time 
series data mining, Pattern Recognition Letters, vol. 41, pp. 23-33, 2014.

55. A. Rangel-Díaz de la Vega, Y. Villuendas-Rey, C. Yáñez-Márquez, O. Camacho-Nieto, and I. López-Yáñez. Impact of Imbalanced Datasets Preprocessing in the Performance of Associative Classifiers,Applied Sciences, Vol. 10, 2779, pp. 1-19, 2020.

56. M. Aldape-Pérez, A. Alarcón-Paredes, C. Yáñez-Márquez, I. López-Yáñez, and O. Camacho-Nieto. An Associative Memory Approach to Healthcare Monitoring and Decision Making,Sensors, Vol. 18(8), 2690, pp. 1-11, 2018.

57. C. Yáñez-Márquez, M. Aldape-Perez, I. López-Yáñez, and O. Camacho-Nieto. Emerging computational tools: Impact on engineering education and computer science learning, International Journal of Engineering Education, pp. 533-542, 2014.

58. M. Aldape-Pérez, C. Yáñez-Márquez, O. Camacho-Nieto, I. López-Yáñez, and A.-J. Argüelles-Cruz. Collaborative learning based on associative models: Application to pattern classification in medical datasets, Computers in Human Behavior, vol. 51, pp. 771-779, 2015.

59. A. Alarcón-Paredes, Z. Rebolledo-Nandi, I. P. Guzmán-Guzmán, C. Yáñez-Márquez, and G. A. Alonso. A non-invasive glucose level estimation in a multi-sensing health care monitoring system, Technology and Health care, Vol. 26, pp. 203-208, 2018.

60. A. Ferreira-Santiago, C. Yanez-Marquez, I. Lopez-Yanez, O. Camacho-Nieto, M. Aldape-Perez, and A. J. Arguelles-Cruz. Enhancing engineering education through link prediction in social networks, International Journal of Engineering Education, pp. 1566-1578, 2016.

61. S. Cerón-Figueroa, I. López-Yáñez, Y. Villuendas-Rey, O. Camacho-Nieto, M. Aldape-Pérez, and C. Yáñez-Márquez. Instance-based ontology matching for open and distance learning materials,International Review of Research in Open and Distributed Learning, Vo. 18, pp. 177-195, 2017.

62. A. García-Floriano, A. Ferreira-Santiago, C. Yáñez-Márquez, O. Camacho-Nieto, M. Aldape-Pérez, and Y. Villuendas-Rey. Social Web Content Enhancement in a Distance Learning Environment: Intelligent Metadata Generation for Resources, International Review of Research in Open and Distributed Learning, vol. 18, pp. 161-176, 2017.

63. S. Ortiz-Ángeles, Y. Villuendas-Rey, I. López-Yáñez, O. C. Nieto, and C. Yáñez-Márquez. Electoral Preferences Prediction of the YouGov Social Network Users Based on Computational Intelligence Algorithms, J. UCS, vol. 23, pp. 304-326, 2017.
64. R. Ramírez-Rubio, M. Aldape-Pérez, C. Yáñez-Márquez, I. López-Yáñez, and O. Camacho-Nieto. Pattern classification using smallest normalized difference associative memory, Pattern Recognition Letters, vol. 93, pp. 104-112, 2017.

65. Y. Villuendas-Rey, C. F. Rey-Benguría, Á. Ferreira-Santiago, O. Camacho-Nieto, and C. Yáñez-Márquez. The naïve associative classifier (NAC): a novel, simple, transparent, and accurate classification model evaluated on financial data, Neurocomputing, vol. 265, pp. 105-115, 2017.

66. J. A. Antón-Vargas, Y. Villuendas-Rey, C. Yáñez-Márquez, I. López-Yáñez, and O. Camacho-Nieto. Improving the performance of an associative classifier by Gamma rough sets based instance selection, International Journal of Pattern Recognition and Artificial Intelligence, vol. 32, p. 1860009, 2018.

67. E. Barroso, Y. Villuendas, and C. Yanez. Bio-inspired algorithms for improving mixed and incomplete data clustering, IEEE Latin America Transactions, vol. 16, pp. 2248-2253, 2018.

68. M. Aldape-Pérez, C. Yáñez-Márquez, O. Camacho-Nieto, and A. Ferreira-Santiago. Feature selection using associative memory paradigm and parallel computing,Computación y Sistemas, Vol. 17, pp. 41-52, 2013.

69. Y. O. Serrano-Silva, Y. Villuendas-Rey, and C. Yáñez-Márquez. Automatic feature weighting for improving financial Decision Support Systems, Decision Support Systems, vol. 107, pp. 78-87, 2018.

70. Y. Villuendas-Rey, M. D. Alanis-Tamez, C. Rey-Benguría, C. Yáñez-Márquez, and O. C. Nieto. Medical Diagnosis of Chronic Diseases Based on a Novel Computational Intelligence Algorithm, $J$. UCS, vol. 24, pp. 775-796, 2018.

71. C. Yáñez-Márquez, I. López-Yáñez, M. Aldape-Pérez, O. Camacho-Nieto, A. J. Argüelles-Cruz, and Y. Villuendas-Rey. Theoretical Foundations for the Alpha-Beta Associative Memories: 10 Years of Derived Extensions, Models, and Applications, Neural Processing Letters, vol. 48, pp. 811-847, 2018.

72. J. E. Luján-García, M. A. Moreno-Ibarra, Y. Villuendas-Rey, and C. Yáñez-Márquez. Fast COVID-19 and Pneumonia Classification Using Chest X-ray Images,Mathematics, Vol. 8, 1423, pp. 1-19 2020.

73. J. L. Velázquez-Rodríguez, Y. Villuendas-Rey, C. Yáñez-Márquez, I. López-Yáñez, and $O$. Camacho-Nieto. Granulation in Rough Set Theory: A novel perspective, International Journal of Approximate Reasoning, Vol. 124, pp. 27-39, 2020.

74. Y. Villuendas-Rey, J. A. Hernández-Castaño, O. Camacho-Nieto, C. Yáñez-Márquez, and I. López-Yañez. NACOD: A Naïve Associative 
Classifier for Online Data, IEEE Access, vol. 7, pp. 117761-117767, 2019.

75. Y. Villuendas-Rey, C. Yáñez-Márquez, J. A Antón-Vargas, and I. López-Yáñez. An Extension of the Gamma Associative Classifier for Dealing With Hybrid Data, IEEE Access, vol. 7, pp. 64198-64205, 2019.

76. C. Yáñez-Márquez. Toward the bleaching of the black boxes: minimalist machine learning. $I T$ Professional, Vol. 22, pp. 51-56, 2020.

77. C. Yanez-Marquez, I. Lopez-Yanez, O. Camacho-Nieto, and A. J. Arguelles-Cruz. BDD-based algorithm for the minimum spanning tree in wireless ad-hoc network routing, IEEE Latin America Transactions, vol. 11, pp. 600-601, 2013.

78. J. A. Hernández-Castaño, Y. Villuendas-Rey, O. Camacho-Nieto, and C. Yáñez-Márquez. Experimental platform for intelligent computing (EPIC), Computación y Sistemas, vol. 22, pp. 245-253, 2018.

79. S. Ortiz-Ángeles, Y. Villuendas-Rey, C. Yáñez-Márquez, I. López-Yáñez, and O. Camacho-Nieto. Determining Electoral Preferences in Mexican Voters by Computational Intelligence Algorithms,IEEE Latin America Transactions, Vol. 18, pp. 704-713, 2020.

80. O. Camacho-Nieto, C. Yáñez-Márquez, and Y. Villuendas-Rey. Undersampling Instance Selection for Hybrid and Incomplete Imbalanced Data,Journal of Universal Computer Science (J.UCS), Vol. 26, pp. 698-719, 2020.

81. A. Rangel-Díaz de la Vega, Y. Villuendas-Rey, C. Yáñez-Márquez, and O. Camacho-Nieto. The Naïve Associative Classifier with Epsilon disambiguation,IEEE Access, $\mathrm{Vol} \quad 8, \quad \mathrm{pp}$. 51862-51870, 2020.

82. D. González-Patiño, Y. Villuendas-Rey, A. J. Argüelles-Cruz, O. Camacho-Nieto, and C. Yáñez-Márquez. AISAC: An Artificial Immune System for Associative Classification Applied to Breast Cancer Detection,Applied Sciences, Vol. 10, 515, pp. 1-22, 2020.

83. E. Ventura-Molina, A. Alarcón-Paredes, M. Aldape-Pérez, C. Yáñez-Márquez, and G. Adolfo-Alonso. Gene selection for enhanced classification on microarray data using a weighted k-NN based algorithm,Intelligent Data Analysis, Vol. 23, pp. 241-253, 2019.

84. C. Lopez-Martin. Applying a general regression neural network for predicting development effort of short-scale programs, Neural Computing and Applications, Vol. 20, pp. 389-401, 2011.

85. A. Chavoya, I. R. Andalon-Garcia, C. Lopez-Martin, and M. E. Meda-Campaña. Use of evolved artificial regulatory networks to simulate $3 \mathrm{D}$ cell differentiation,Biosystems, Vol. 102, pp. 41-48, 2010.
86. B. López-Carrera, B., and C. Yáñez-Márquez. A simple model for the entropy of a system with interacting particles,IEEE Access, Vol. 7, pp. 108969-108979, 2019.

87. 79 S. Sharma, and R. Agarwal. Optimizing QoS parameters using computational intelligence in MANETS. In 2017 International Conference on Computing, Commu-nication and Automation (ICCCA) (pp. 708-715). IEEE, 2017.

88. 80 A. J. A Cruz, M. M. De Luis, P. E. M. Aguilera, and C. Y. Márquez. Mobile system surveillance for vehicular pollutants emission, based on $\mathrm{Wi}-\mathrm{Fi}$ ad-hoc network. In Ubiquitous Computing and Ambient Intelligence. Context-Awareness and Con-text-Driven Interaction (pp. 294-302). Springer, Cham., 2013.

89. 81. C. López-Martın, I. Lopez-Yanez, and C. Yanez-Marquez. Application of Gamma classifier to development effort prediction of software projects. Appl. Math, Vol. 6(3), 411-418, 2012.

90. 82 K. Khamforoosh. Clustered Balanced Minimum Spanning Tree for Routing and Energy, in Proceedings of Symposium on Wireless Technology and Applications (ISWTA), pp. 56-59, 2011.

91. 83 I. López-Yáñez, C. Yáñez-Márquez, and O. Camacho-Nieto. Binary Decision Diagrams, IPN-CIDETEC Series, Mexico, 2007.

92. 84 R. Bryant. Graph-Based Algorithms for Boolean Function Manipulation, Transactions on Computers, C-35, pp. 677-691, 1986.

93. 85 R. Sangireddy, and A. K. Somani. High-speed IP routing with binary decision diagrams based hardware address lookup engine, IEEE Journal on Selected Areas in Communications, Vol. 21, pp. 513-521, 2003.

94. 86 B. Bolling. On symbolic OBDD-based algorithms for the minimum spanning tree problem, Theoretical Computer Science, Vol. 447, pp. 2-12, 2012.

95. N. Nawaz. Artificial Intelligence Face Recognition for Applicant Tracking System. International Journal of Emerging Trends in Engineering Research, Vol. 7, no. 12, 2019.

96. N.-Kt Nguyen. A novel improving technology to intelligent controllers - a typical case study for turbine speed regulation of a smart hydropower plant. International Journal of Emerging Trends in Engineering Research, Vol. 8, No. 6, pp. 2388 - 2394, 2020.

97. O. Dahiya, K. Solanki, S. Dalal, and A. Dhankhar. An Exploratory Retrospective Assessment on the Usage of Bio- inspired Computing Algorithms for Optimization. International Journal of Emerging Trends in Engineering Research, Vol. 8, No. 2, pp. 414-434, 2020.

98. M. S. Kumar, S. Inthiyaz, M.Aditya, P. Rupanjani, B. Aravind, M. Mukesh, S. K.. Tulasi. Implementation 
of GDI Logic for Power Efficient SRAM Cell with Dynamic Threshold Voltage Levels, International Journal of Emerging Trends in Engineering Research, Vol. 7, No. 12, pp.902-906, 2019.

99. H. Khudov, S. Yarosh, V. Savran, A. Zvonko, A. Shcherba, P. Arkushenko. The technique of research on the development of radar methods of small air objects detection, International Journal of Emerging Trends in Engineering Research, Vol. 8, no.7, pp. 3708-3715, 2020. 